\title{
Effect of incubation on freezability of cholesterol-loaded cyclodextrin treated buffalo (Bubalus bubalis) spermatozoa
}

\author{
S. A. Lone ${ }^{1}$, J. K. Prasad², S. K. Ghosh², G. K. Das², B. Balamurugan², R. Katiyar² and M. R. Verma ${ }^{3}$
}

1. Division of Animal Reproduction, Gynecology \& Obstetrics, National Dairy Research Institute, Karnal - 132001, Haryana, India; 2. Germplasm Centre, Division of Animal Reproduction, Indian Veterinary Research Institute, Izatnagar, Bareilly - 243122, Uttar Pradesh, India; 3. Division of Livestock Economics and Statistics, Indian Veterinary Research Institute, Izatnagar, Bareilly - 243122, Uttar Pradesh, India.

Corresponding author: S. A. Lone, e-mail: drloneshabir@gmail.com,

JKP: jkprasad2001@yahoo.com, SKG: subratakghosh@yahoo.com, GKD: gkdasivri@gmail.com, BB: balavet07@gmail.com, RK: rahul.katiyarvet@gmail.com, MRV: medramverma@rediffmail.com Received: 02-09-2015, Revised: 21-12-2015, Accepted: 29-12-2015, Published online: 18-02-2016

doi: 10.14202/vetworld.2015.182-185 How to cite this article: Lone SA, Prasad JK, Ghosh SK, Das GK, Balamurugan B, Katiyar R, Verma MR (2016) Effect of incubation on freezability of cholesterol-loaded cyclodextrin treated buffalo (Bubalus bubalis) spermatozoa, Veterinary World 9(2): 182-185.

\begin{abstract}
Aim: The aim of this study was to investigate the effect of incubation on freezability of cholesterol loaded cyclodextrin (CLC) treated buffalo spermatozoa.

Materials and Methods: Semen samples with mass motility of $3+$ and greater, collected from Murrah buffalo bulls were utilized. Immediately after collection, four equal groups of semen sample were made. Group I was kept as control and diluted with Tris upto concentration of $60 \times 10^{6} \mathrm{sperm} / \mathrm{ml}$, where as Groups II, III, and IV were treated with CLC at $3 \mathrm{mg} / 120 \times 10^{6}$ spermatozoa, incubated at $37^{\circ} \mathrm{C}$ for action of CLC for 10,15 and $20 \mathrm{~min}$, respectively, and diluted with tris upto concentration of $60 \times 10^{6} \mathrm{sperm} / \mathrm{ml}$. All groups were subjected to equilibration and freezing. The evaluation of semen samples from all groups was carried out at fresh, pre-freeze and post-thaw stage for progressive motility, viability and hypoosmotic swelling response (HOS response).

Results: At the pre-freeze stage, significantly $(\mathrm{p}<0.05)$ higher percentage of progressive motility and viability was observed in treatment groups as compared to control with no significant difference among treatment groups. HOS response was significantly $(\mathrm{p}<0.05)$ higher in treatment groups as compared to control at pre-freeze stage. At post-thaw stage, significantly $(\mathrm{p}<0.05)$ higher percentage of progressive motility, viability and HOS response was recorded in Group II as compared to control and other treatment groups (III and IV). Group II retained significant post-thaw motility and viability at various post-thaw incubation periods.
\end{abstract}

Conclusion: Incubation period of $10 \mathrm{~min}$ for CLC treated buffalo spermatozoa yielded significantly higher results in terms of freezability as compared to incubation for 15 and $20 \mathrm{~min}$.

Keywords: buffalo spermatozoa, cholesterol loaded cyclodextrin, incubation.

\section{Introduction}

Plasma membrane integrity is essential for spermatozoa to protect them from harmful effects of cryopreservation. Adding cholesterol or its analogs to the medium reduces capacitation process [1]. Due to hydrophobic nature of cholesterol, it is insoluble in aqueous semen diluents. Cyclodextrins, which are obtained by enzymatic degradation of starch, are capable of inserting cholesterol into cell membranes due to the presence of an internal hydrophobic core, in addition to an external hydrophilic face [2].

Addition of CLC to semen significantly increases progressive motility, viability, acrosomal integrity [3,4], and hypo-osmotic swelling (HOS) responsive spermatozoa [3]. CLC improves in vitro

Copyright: Lone, et al. Open Access. This article is distributed under the terms of the Creative Commons Attribution 4.0 International License (http://creativecommons.org/licenses/by/4.0/), which permits unrestricted use, distribution, and reproduction in any medium, provided you give appropriate credit to the original author(s) and the source, provide a link to the Creative Commons license, and indicate if changes were made. The Creative Commons Public Domain Dedication waiver (http://creativecommons.org/ publicdomain/zero/1.0/) applies to the data made available in this article, unless otherwise stated. fertilizing ability and reduces ultrastructural damages to spermatozoa plasma membrane [4]. CLC has been used for modification of cholesterol content in buffalo spermatozoa [5].

After treating the spermatozoa with CLC, some incubation period is needed for transfer of cholesterol into sperm plasma membrane [6]. Incubation of CLC treated spermatozoa at $22^{\circ} \mathrm{C}$ or $37^{\circ} \mathrm{C}$ for 15,30 and $60 \mathrm{~min}$ have revealed similar beneficial effects in terms of cryopreservation of cattle bull semen [7]. However, no study has been conducted regarding the effect of different incubation periods on freezability of CLC treated buffalo spermatozoa.

The aim of this study was to investigate the effect of incubation on freezability of CLC treated buffalo spermatozoa.

\section{Materials and Methods}

\section{Ethical approval}

No ethical approval was necessary to pursue this research work.

\section{Climatic conditions and experimental animals}

Geographical location of Bareilly is at an altitude of $169 \mathrm{~m}$ above mean sea level and at the latitude of 
$28.22^{\circ} \mathrm{N}$ and longitude of $79.22^{\circ} \mathrm{E}$. Bareilly is known to have a moderate climate. Summer temperature goes up to $40^{\circ} \mathrm{C}$, where as winter temperature goes down up to $8^{\circ} \mathrm{C}$. The rainy season starts in June and extends up to September with humid and warm conditions. Three healthy breeding buffalo bulls maintained at Germplasm Center, Division of Animal Reproduction, Indian Veterinary Research Institute (IVRI), Izatnagar, Bareilly were utilized for the study. These bulls were kept under identical feeding and management conditions during the entire course of the investigation.

\section{Chemicals}

All chemicals were reagent grade and purchased from Sigma-Aldrich (St. Louis, MO, USA).

\section{CLC preparation}

Methyl- $\beta$-CLC was loaded with cholesterol as described [7]. Briefly, $200 \mathrm{mg}$ of cholesterol was dissolved in $1 \mathrm{ml}$ of chloroform in a glass tube. In the second glass tube, $1 \mathrm{~g}$ of methyl- $\beta$-cyclodextrin was dissolved in $2 \mathrm{ml}$ of methanol. A $0.45 \mathrm{ml}$ aliquot of the cholesterol solution was added to the cyclodextrin solution, and the mixture was stirred until the combined solution appeared clear. This was followed by pouring of the mixture into a glass petri-dish and removing of solvents using a stream of nitrogen gas. The resulting crystals were allowed to dry for an additional $24 \mathrm{~h}$ and then were removed from the dish and stored in a glass container at $22^{\circ} \mathrm{C}$. A working solution of CLC was prepared by adding $50 \mathrm{mg}$ of CLC to $1 \mathrm{ml}$ of tris diluent at $37^{\circ} \mathrm{C}$ and mixing the solution briefly using a vortex mixer.

\section{Collection of semen and its processing}

Semen was collected using an artificial vagina as per the standard method. A total of 24 ejaculates, eight from each bull $(8 \times 3=24)$ were collected. Only ejaculates with mass motility $\geq 3+$ were used in the study. Immediately after collection of semen, each ejaculate was divided into four groups. Group I: Control (without addition of CLC and diluted with tris-egg yolk-glycerol dilutor up to $60 \times 10^{6}$ spermatozoa $/ \mathrm{ml}$. In Groups II, III and IV, CLC was added at $3 \mathrm{mg} / 120 \times 10^{6}$ spermatozoa and were incubated at $37^{\circ} \mathrm{C}$ for 10 , 15 and $20 \mathrm{~min}$, respectively, for entry of cholesterol into sperm plasma membrane. After incubation each sample was diluted with tris-egg yolk-glycerol dilutor up to $60 \times 10^{6}$ spermatozoa $/ \mathrm{ml}$. Initial progressive motility, viability and HOS response were recorded in each group.

\section{Semen freezing and its evaluation}

French midi straws $(0.5 \mathrm{ml})$ were filled with the extended semen samples, sealed with polyvinyl alcohol powder and kept for $3 \mathrm{~h}$ at $5^{\circ} \mathrm{C}$ for equilibration. After equilibration, straws were kept in automatic programable biological cell freezer (IMV technology, France) until temperature of straws reached $-145^{\circ} \mathrm{C}$. Then, straws were plunged into liquid nitrogen $\left(-196^{\circ} \mathrm{C}\right)$ for storage. Semen samples were evaluated at pre-freeze and post-thaw stage for progressive motility, viability and HOS response. The viability of spermatozoa was assessed using Eosin-Nigrosin stain described by Campbell et al. [8].

\section{Statistical analysis}

Data were statistically analyzed by one-way ANOVA and results were expressed as mean \pm standard error. Means were compared using Tukey's multiple comparison test. The statistical package of Graph pad prism, San Diego, USA was used for analyzing the data.

\section{Results and Discussion}

Effect of incubation on individual progressive motility, viability and HOS response at fresh stage

The initial progressive motility of a semen sample gives a good indication of the fertility of the bull and ability of spermatozoa to withstand the stress of the cryopreservation process. The percent individual progressive motility of spermatozoa was $82.29 \pm 0.67,82.50 \pm 0.65,82.50 \pm 0.65$ and $82.29 \pm 0.67$, respectively, in Groups I, II, III and IV (Table-1). The percent individual progressive motility was comparable to the values reported by workers $[5,9]$ but higher than the values reported by Sannat et al. and Bhakat et al. [10,11]. The viability of spermatozoa in a semen sample is significantly and positively correlated with initial motility, post-thaw motility, and fertility of spermatozoa. Percentage of viable spermatozoa was $87.45 \pm 0.66,87.79 \pm 0.68,87.16 \pm 0.69$, and $87.16 \pm 0.65$, respectively, in Group I, II, III and IV (Table-1). The percentage of viable spermatozoa was comparable to values reported by Ramteke [12], higher than the values reported by Rajoriya et al. [5] but lower than the values of Shukla and Misra [13]. The difference may be attributed to the various factors that affect motility and viability like bull's age, season, frequency of collection and sexual excitement before semen collection.

Hypo-osmotic swollen spermatozoa (\%) were $77.16 \pm 0.70,77.54 \pm 0.71,77.33 \pm 0.70$ and $77.25 \pm 0.70$, respectively, in Group I, II and III and IV (Table-1). No significant difference in mean values of hypo-osmotic swollen spermatozoa (\%) was observed among Groups I, II, III and IV. The percent HOS positive spermatozoa in our study was higher than the values reported by Kumar [3] and Kadirvel et al. [14] but lower than that reported by Rajoriya et al. [15]. The higher percentage of HOS positive spermatozoa in our study indicates higher percentage of membrane intact spermatozoa.

Effect of incubation on individual progressive motility, viability and HOS response at pre-freeze and post-thaw stage

The percent individual progressive motility at pre-freeze was significantly $(p<0.05)$ higher in treatment groups as compared to control group. No significant difference in percent individual progressive motility was observed among treatment 
Groups (II, III, and IV). At post-thaw stage, group II had highest $(59.58 \pm 0.41)$ individual progressive motility compared to other three groups. A significantly $(p<0.05)$ higher percentage of progressively motile spermatozoa in Group II was observed as compared to Group I (control). The post-thaw progressive motility was significantly $(\mathrm{p}<0.05)$ higher in Group II as compared to Groups (III and IV). No significant difference was observed in mean values of progressively motile spermatozoa among Groups (III and IV). In our study about $4 \%$ increase in individual progressive motility in Group II was recorded as compared to Group III (Table-2). At pre-freeze stage, percent live spermatozoa was significantly $(\mathrm{p}<0.05)$ higher in the treatment groups as compared to control group (Group I). No significant difference was observed in mean percent live spermatozoa among treatment groups. The mean post-thaw percent live spermatozoa was higher in treatment groups with Group II having significantly $(\mathrm{p}<0.05)$ higher mean post-thaw percent live spermatozoa compared to Group I (control). Percent mean sperm viability was significantly $(\mathrm{p}<0.05)$ higher in Group II as compared to Groups (III and IV). However, no significant difference in post-thaw percent live spermatozoa was observed between Groups III and IV. On an average 3\% increase in percentage of live spermatozoa was observed in Group II as compared to Group III (Table-2). Our study revealed that at pre-freeze stage, incubation for 10, 15 and 20 min yielded no significant difference in terms of progressive motility and viability of buffalo spermatozoa among treatment groups. However at post-thaw stage, $10 \mathrm{~min}$ incubation revealed significant results in terms of freezability of buffalo spermatozoa as compared to incubation at higher 15 and $20 \mathrm{~min}$.

At pre-freeze stage, percent HOS response was significantly $(\mathrm{p}<0.05)$ higher in treatment groups as compared to Group I (control). No significant difference in HOS response was observed between
Groups III and IV. At post-thaw stage, percent HOS response was significantly higher in Group II than all other groups. Among treatment groups, the HOS response was significantly $(\mathrm{p}<0.05)$ higher in Group II as compared to Groups III and IV. No significant difference in HOS response was observed between Groups III and IV at pre-freeze and post-thaw stage. At post-thaw stage, there was an increase of about 3\% HOS responsive spermatozoa in Group II as compared to Group III (Table-2).

This clearly indicated $10 \mathrm{~min}$ incubation has beneficial effect on membrane integrity. No literature could be traced to compare our finding in the case of buffalo semen.

All four groups were also subjected to postthaw incubation test to observe sustainability of postthaw motility and viability after a prolonged duration of thawing (Tables-3 and 4). Our study revealed a significant reduction in post-thaw motility and viability from $0 \mathrm{~min}$ to $120 \mathrm{~min}$. Group II withstands satisfactory post-thaw motility $(50.00 \%)$ even after 30 min of post-thaw incubation period (Table-3). In Group II, reduction in post-thaw livability was significantly less as compared to Groups I, III and IV (Table-4). Group II showed satisfactory viability $(55.66 \%)$ at $30 \mathrm{~min}$ of post-thaw incubation period (Table-4). In the present study, results in terms of post-thaw incubation test with respect to post-thaw motility and viability were significantly $(p<0.01)$ better in Group II as compared to other three groups.

\section{Conclusion}

It is concluded that spermatozoa viability, motility, HOS response and post-thaw incubation response were better in Group II, in which incubation was carried out for $10 \mathrm{~min}$. Furthermore, even after $30 \mathrm{~min}$ of post-thaw incubation, Group II (10 $\mathrm{min})$ retained about $50 \%$ motile and $55 \%$ viable spermatozoa than other groups.

Table-1: Mean \pm SE of effect of incubation on progressive motility, viability and HOS response at fresh stage.

\begin{tabular}{lcccc}
\hline Seminal attribute & Group I & Group II & Group III & Group IV \\
\hline Progressive motility (\%) & $82.29 \pm 0.67$ & $82.50 \pm 0.65$ & $82.50 \pm 0.65$ & $82.29 \pm 0.67$ \\
Viability (\%) & $87.45 \pm 0.66$ & $87.79 \pm 0.68$ & $87.16 \pm 0.69$ & $87.16 \pm 0.65$ \\
HOS response (\%) & $77.16 \pm 0.70$ & $77.54 \pm 0.71$ & $77.33 \pm 0.70$ & $77.25 \pm 0.70$ \\
\hline
\end{tabular}

$\mathrm{SE}=$ Standard error, HOS=Hypo-osmotic swelling

Table-2: Mean \pm SE of effect of incubation on progressive motility, viability and HOS response at pre-freeze and post-thaw stage of buffalo spermatozoa.

\begin{tabular}{|c|c|c|c|c|c|c|}
\hline \multirow[t]{2}{*}{ Groups } & \multicolumn{2}{|c|}{ Progressive motility (\%) } & \multicolumn{2}{|c|}{ Viability (\%) } & \multicolumn{2}{|c|}{ HOS response (\%) } \\
\hline & Pre-freeze & Post-thaw & Pre-freeze & Post-thaw & Pre-freeze & Post-thaw \\
\hline Group I & $71.25 \pm 0.68^{b}$ & $50.58 \pm 0.39^{c}$ & $75.29 \pm 0.64^{b}$ & $55.95 \pm 0.39^{c}$ & $66.70 \pm 0.64^{b}$ & $50.20 \pm 1.13^{c}$ \\
\hline Group II & $76.45 \pm 0.64^{a}$ & $59.58 \pm 0.41^{a}$ & $81.29 \pm 0.61^{\mathrm{a}}$ & $64.62 \pm 0.35^{\mathrm{a}}$ & $73.20 \pm 0.71^{\mathrm{a}}$ & $60.08 \pm 1.09^{a}$ \\
\hline Group III & $75.83 \pm 0.62^{\mathrm{a}}$ & $55.62 \pm 0.42^{b}$ & $79.87 \pm 0.63^{a}$ & $61.45 \pm 0.34^{b}$ & $71.62 \pm 0.70^{a}$ & $57.75 \pm 1.18^{\mathrm{b}}$ \\
\hline Group IV & $74.58 \pm 0.77^{a}$ & $54.74 \pm 0.35^{b}$ & $78.95 \pm 0.65^{a}$ & $60.25 \pm 0.31^{b}$ & $70.25 \pm 0.70^{a}$ & $55.58 \pm 1.14^{b}$ \\
\hline
\end{tabular}

Values bearing different superscripts in column ( $a, b$ and $c)$ differ significantly at $5 \%(p<0.05)$. SE=Standard error, HOS=Hypo-osmotic swelling 
Table-3: Mean \pm SE of effect of incubation on post-thaw motility at various post-thaw incubation periods.

\begin{tabular}{lcccc}
\hline Time (min) & Group I (control) & Group II & Group III & Group IV \\
\hline 0 & $50.58 \pm 0.39^{\mathrm{c}}$ & $59.58 \pm 0.41^{\mathrm{A}}$ & $55.62 \pm 0.42^{\mathrm{B}}$ & $54.74 \pm 0.35^{\mathrm{B}}$ \\
15 & $41.25 \pm 0.35^{\mathrm{c}}$ & $55.20 \pm 0.31^{\mathrm{a}}$ & $50.20 \pm 0.41^{\mathrm{b}}$ & $50.00 \pm 0.37^{\mathrm{b}}$ \\
30 & $31.87 \pm 0.33^{\mathrm{c}}$ & $50.00 \pm 0.33^{\mathrm{a}}$ & $44.58 \pm 0.44^{\mathrm{b}}$ & $43.25 \pm 0.41^{\mathrm{b}}$ \\
45 & $23.54 \pm 0.35^{\mathrm{d}}$ & $45.00 \pm 0.33^{\mathrm{a}}$ & $38.12 \pm 0.44^{\mathrm{b}}$ & $36.91 \pm 0.41^{\mathrm{c}}$ \\
60 & $15.20 \pm 0.43^{\mathrm{d}}$ & $40.00 \pm 0.33^{\mathrm{a}}$ & $32.87 \pm 0.37^{\mathrm{b}}$ & $30.58 \pm 0.46^{\mathrm{c}}$ \\
120 & $6.66 \pm 0.27^{\mathrm{d}}$ & $26.87 \pm 0.44^{\mathrm{a}}$ & $19.16 \pm 0.32^{\mathrm{b}}$ & $16.45 \pm 0.38^{\mathrm{c}}$ \\
\hline
\end{tabular}

Values bearing different superscripts in upper case letters in a row differ significantly at $5 \%(p<0.05)$ and in lower case letters in a row differ significantly at $1 \%(\mathrm{p} \leq 0.01) . \mathrm{SE}=$ Standard error

Table-4: Mean \pm SE of effect of incubation on post-thaw viability at various post-thaw incubation periods.

\begin{tabular}{lcccc}
\hline Time (min) & Group I (control) & Group II & Group III & Group IV \\
\hline 0 & $55.95 \pm 0.396^{\mathrm{c}}$ & $64.62 \pm 0.359^{\mathrm{A}}$ & $61.45 \pm 0.347^{\mathrm{B}}$ & $60.25 \pm 0.319^{\mathrm{B}}$ \\
15 & $47.20 \pm 0.365^{\mathrm{c}}$ & $59.87 \pm 0.317^{\mathrm{a}}$ & $55.41 \pm 0.378^{\mathrm{b}}$ & $54.00 \pm 0.308^{\mathrm{b}}$ \\
30 & $37.66 \pm 0.371^{\mathrm{d}}$ & $55.08 \pm 0.293^{\mathrm{a}}$ & $49.58 \pm 0.391^{\mathrm{b}}$ & $47.00 \pm 0.285^{\mathrm{c}}$ \\
45 & $29.20 \pm 0.384^{\mathrm{d}}$ & $49.95 \pm 0.328^{\mathrm{a}}$ & $43.37 \pm 0.400^{\mathrm{b}}$ & $40.50 \pm 0.426^{\mathrm{c}}$ \\
60 & $20.59 \pm 0.397^{\mathrm{d}}$ & $44.79 \pm 0.307^{\mathrm{a}}$ & $37.16 \pm 0.366^{\mathrm{b}}$ & $33.54 \pm 0.465^{\mathrm{c}}$ \\
120 & $11.37 \pm 0.262^{\mathrm{d}}$ & $32.33 \pm 0.426^{\mathrm{a}}$ & $23.91 \pm 0.334^{\mathrm{b}}$ & $20.08 \pm 0.383^{\mathrm{c}}$ \\
\hline
\end{tabular}

Values bearing different superscripts in upper case letters in a row differ significantly at $5 \%(p<0.05)$ and in lower case letters in a row differ significantly at $1 \%(p \leq 0.01) . S E=S t a n d a r d$ error

\section{Authors' Contributions}

SAL planned and performed research work for his MVSc thesis program in collaboration with guide (JKP). Author is thankful SKG and GKD for providing lab facility during his research work. RK and BB helped in collection of sample and estimation of parameters during his research work. MRV helped in statistical analysis of data. All authors read and approved the final manuscript.

\section{Acknowledgments}

The authors are thankful to Director, IVRI, Izatnagar- 243122, Bareilly for providing facilities and fund during thesis research work of first author. Furthermore, we thank Head Animal Reproduction Division IVRI for providing necessary suggestions.

\section{Competing Interests} interests.

The authors declare that they have no competing

\section{References}

1. Serin, I., Aksoy, M. and Ceylan, A. (2011) Cholesterolloaded cyclodextrin inhibits premature acrosomal reactions in liquid-stored spermatozoa. Anim. Reprod. Sci., 123(1-2):106-111.

2. Dodziuk, H. (2006) Molecules with holes-cyclodextrins. In: Dodziuk, H., editor. Cyclodextrins and their Complexes. Wiley-VCH Verlag GmbH \& Co., Weinheim, Germany. p1-30.

3. Kumar, A. (2012) Studies on effect of cholesterol loaded cyclodextrin on freezability and in vitro fertility of buffalo spermatozoa. Ph.D. Thesis Submitted to Deemed University IVRI,Izatnagar, U.P, India.

4. Rajoriya, J.S (2014) Studies on effect of cholesterol loaded cyclodextrin on cryocapacitation and in vitro fertility of cryopreserved buffalo spermatozoa. PhD Thesis. Submitted to Deemed University, IVRI, Izatnagar, U.P. India.

5. Rajoriya, J.S., Prasad, J.K., Ghosh, S.K., Ramteke, S.,
Barik, N.C., Das, G.K. and Pande, M. (2014) Cholesterol loaded cyclodextrin increases freezability of buffalo bull (Bubalus bubalis) spermatozoa by increasing cholesterol to phospholipid ratio. Vet. World, 7(9):702-706.

6. Purdy, P.H. and Graham, J.K. (2004) Effect of adding cholesterol to bull sperm membraneson sperm capacitation, the acrosome reaction and fertility. Biol. Reprod., 71(2):522-527.

7. Purdy, P.H. and Graham, J.K. (2004a) Effect of cholesterol-loaded cyclodextrin on the cryosurvival of bull sperm. Cryobiology, 48: 36-45.

8. Campbell, R.G., Hancock, J.L. and Rothschild, L. (1953) Counting live and dead bullspermatozoa. J. Exp. Biol., 30: 44-45.

9. Singh, M., Ghosh, S.K., Prasad, J.K., Kumar, A., Tripathi, R.P., Bhure, S.K. and Srivastava, N. (2014) Seminal PDC-109 protein vis-à-vis cholesterol content and freezability of buffalo spermatozoa. Anim. Reprod. Sci., 144(1-2): 22-29.

10. Sannat, C., Nair, A., Sahu, S.B., Sahasrabudhe, S.A., Kumar, A., Gupta, A.K, and Shende, R.K. (2015) Effect of species, breed and age on bacterial load in bovine and bubaline semen. Vet. World, 8(4):461-466.

11. Bhakat, M., Mohanty, T.K., Singh, S., Gupta, A.K., Chakravarty, A.K. and Singh, P. (2015) Influence of semen collector on semen characteristics of Murrah buffalo and Crossbred bulls. Adv. Anim.Vet. Sci., 3(4): 253-258.

12. Ramteke, S.S. (2014) Purification of PDC-109 and standardization of Anti-PDC-109 level to minimize buffalo spermatozoa cryodamage. $\mathrm{PhD}$ Thesis. Submitted to Deemed University, IVRI, Izatnagar, U.P. India.

13. Shukla, M.K. and Misra, A.K. (2005) Correlation between seminal characteristics in Murrah buffaloes. Indian J. Anim. Sci., 75: 263-266.

14. Kadirvel, G., Kumar, S., Ghosh, S.K. and Perumal, P. (2014) Activity of antioxidative enzymes in fresh and frozen thawed buffalo (Bubalus bubalis) spermatozoa in relation to lipid peroxidation and semen quality. Asian Pac. J. Reprod., 3(3): 210-217.

15. Rajoriya, J.S., Prasad, J.K., Ghosh, S.K., Perumal, P., Kumar, A., Kaushal, S. and Singh, M. (2013) Effects of seasons on enzymatic changes and cholesterol efflux in relation to freezability in Tharparkar bull semen. Asian Pac. J. Reprod., 2(4): 280-288. 